\title{
EVALUATION OF INTERCHANGEABLE GUIDE IN MINIMALLY INVASIVE RIDGE SPLITTING WITH SIMULTANEOUS IMPLANT PLACEMENT (A PROSPECTIVE CLINICAL STUDY)
}

\author{
Sameh O. Elkholy ${ }^{*}{ }_{B D S}$, Abdelaziz F. Khalil ${ }^{2} P h D$, Ahmed O. Sweedan ${ }^{3} P h D$
}

\begin{abstract}
BACKGROUND: The conventional ridge splitting technique offers a feasible and more consistent approach for the challenging narrow alveolar ridge. However, this entails raising of a complete flap to allow an adequate visibility of the osseous defect resulting in disturbance of vascular supply and risk of bone resorption. Stereolithography helps the manufacture of surgical guides using 3D generated models for an accurate placement of implants with minimal invasiveness thus preserving the periosteum.

OBJECTIVES: To assess the precision of dental implant placement in narrow ridges after ridge splitting minimally invasive technique using an interchangeable guide.

MATERIALS AND METHODS: A prospective study was including 5 patients with anterior maxillary narrow ridge. All patients were selected to suit the proposed inclusion and exclusion criteria. Ridge split procedure was performed for all selected subjects assisted with the surgical guide with simultaneous placement of implants. Patients were evaluated by clinical and radiographical assessments with an average of 6 months follow up.

RESULTS: 8 implants were placed. Angular deviations with an average of $2.61 \pm 1.46$ degrees. The mean values of the horizontal deviation at the coronal and apex sides of the implant were $0.70 \pm 0.46 \mathrm{~mm}$ and $0.98 \pm 0.35 \mathrm{~mm}$. While the Vertical deviations (V) with an average of $0.39 \pm 0.29$ $\mathrm{mm}$. There were statistically significant differences between preoperative, immediate postoperative and 6 months postoperative values of bone width and density.

CONCLUSIONS: Alveolar ridge split technique assisted with an interchangeable surgical guide is a feasible and reliable method for placement of dental implants.

KEYWORDS: Ridge splitting, Surgical guide, 3D planning, Minimally invasive technique, Immediate implant. RUNNING TITTLE: Guided ridge splitting with simultaneous implant placement.
\end{abstract}

1 Bachelor of Dental Surgery, Faculty of Dentistry, Alexandria University, Alexandria, Egypt.

2 Professor of Oral and Maxillofacial Surgery Alexandria University, Alexandria, Egypt.

3Lecturer of Oral and Maxillofacial Surgery Department, Faculty of Dentistry, Alexandria University, Alexandria, Egypt.

\section{*Corresponding author:}

E-mail: samehosama2000@gmail.com

\section{INTRODUCTION}

Implant dentistry has long been considered the standard of care for restoring missing teeth. Improving technologies and recent updates refine the field of implant placement widely, however, still remain certain limitations of which the narrow alveolar ridge is regarded the most challenging. Accordingly, many scholars advocated such a challenge with consideration to the analysis, diagnosis and different ways of management (1).

The effectiveness and success of dental implant surgery is largely dependent on the availability of an adequate bony support, with at least 1-1.5 mm bone thickness on both buccal and lingual/palatal sides of the dental implant (2).

Considering a narrow alveolar ridge is the scene, $(<5$ $\mathrm{mm}$ measured at the coronal and apical levels), then the surgical procedure is often achieved in two-stages involving the guided bone regeneration (3). Accordingly, the reduced ridge is still considered a major challenge for successful implant placement. Various techniques have long been advocated to augment the inadequate ridge including, onlay lateral ridge bone grafting (4), horizontal osteodistraction, and guided bone regeneration techniques (5). Such procedures still show some limitations; morbidity at the donor site, higher costs, and increased duration of treatment.

The procedure of ridge splitting is an alternative method to augment the narrow alveolar ridges with an average height. This technique is well reported for management of inadequate ridges as a prerequisite for dental implantation with superior outcomes in favor of the maxilla than the mandible, however, still the accuracy of both osteotomy and implant placement is not well determined as this is an operator dependent procedure based on the surgeon experience and skills (6).

The development of newer diagnostic and imaging technologies including computed tomography (CT) is becoming nowadays the key for successful implant placement (7). The 3D designed surgical guides are fabricated mainly to accurately transfer the preoperative virtual plan and data obtained from the presurgical diagnostic wax up to the 
intraoperative real scene for precise three dimensional implant placement considering the position, depth and angulation. Earlier reports introduced provisional designs of the surgical guides which were limited to define the placement of dental implants in relation to surrounding vital structures. With advancing technologies, the indications of the surgical guides increased and included the proper mesio-distal and buccolingual positioning of implants (8). Then this approach gains more popularity due to the increased accuracy of implant positioning, less overall rehabilitation time, predictable outcomes, and the minimally invasive nature of the procedure (9).

In a word, the current research is implemented to present a technique of an alveolar ridge splitting assisted with an interchangeable surgical guide through a minimally invasive approach, therefore, conservation of the soft and hard tissues, which entail several advantages: 1) Salvage of the overlying periosteum so avoiding complete osseous fractures; 2) improved accuracy of the technique; 3) greatly reducing the surgery time and also the postoperative complications.

The null hypothesis assumes that no effects will be found using the interchangeable surgical guide.

\section{MATERIALS AND METHODS}

This study was approved by the institutional ethical approval board, Faculty of Dentistry, Alexandria University with an informed written consent obtained from all participants. This manuscript was registered in in ClinicalTrials.gov with the protocol ID: NCT04386382.

\section{Patients}

This was a prospective clinical study conducted on five patients (8 implants) with anterior maxillary narrow ridge selected using simple random sample technique.

All patients were selected from the Outpatient Clinic of Oral and Maxillofacial Surgery Department, Faculty of Dentistry, Alexandria University, from November, 2019 to May, 2020.

\section{Inclusion criteria}

Patients with anterior maxillary narrow ridge from $3 \mathrm{~mm}$ to 5 $\mathrm{mm}$ (10) with an adequate alveolar ridge bone height (11), Age ranging from 20-40 years, with an adequate oral hygiene (12), free of any other oral pathology (13) patients agreeing to participate in the research.

\section{Exclusion criteria}

1) Relevant systemic diseases; 2) immunologic disorders and related illnesses; (14) 3) Heavy smokers ( $\geq 25$ cigarettes per day) (15).

\section{Materials}

Interchangeable Stereolithographic surgical guide (Figure 1)

Fabrication and description

An optical scanning of the dental casts was done using Ceramill map 400 (Amman Girbach, Austria). Then the treatment plan and surgical stent were designed using Mimics Innovation Suite 19 TM software (Materialise Mimics software 3D Medical Imaging, Belgium). Using the 3D software, special 3D virtual guide slits and boxes were designed that can accommodate and precisely fit the tools used for the ridge splitting technique. These tools were designed as follows:
External Box: is a hollowed rectangular shaped box with an internal ledge created $1 \mathrm{~mm}$ away from the top aspect of the box. This box accommodates the box shaped guides.

Blade Guide: is a rectangular shaped box that fits precisely into the external box. It contains an internal slit that exactly fits the blade.

Piezotome guide: is a rectangular shaped box that fits precisely into the external box. It contains an internal slit that precisely fits the piezotome tips.

Split chisel guide: is a rectangular shaped box that fits precisely into the external box. It contains an internal slit that exactly fits the split bone chisel.

Drill implant sleeve guide: is a rectangular shaped box that fits precisely into the external box. It contains an implant sleeve for implant placement.

The external box, guides and internal splitting plane complex were temporarily and virtually attached together, then exported as STL objects and then imported into the mimics program.

The resultant 3D virtual stent, blade guide, piezotome guide, split chisel guide and drill implant sleeve guide were exported as STL (stereolithographic) files to a 3D printing machine to build the stent from a photo curable resin material. Sequencing from the different guides

The Sequence of tools designed especially for this technique was used through the external box. First, the blade guide was secured in place to allow the blade to cut an alveolar crestal flap. The Blade guide was then replaced by the Blade handle guide allowing the handle and blade to pass through the slit until a pre- determined depth of $9 \mathrm{~mm}$ was reached. The blade handle guide was then replaced by the Chisel guide to allow the Bone Split Chisel to perform a flapless split. The Chisel guide was then replaced by the Implant guide sleeve.

Implants and Surgical Kit

-Dentium dental implant, two pieces, screw type titanium dental implant.NR line Korea.

-Universal Smart surgical kit (Smart kit, Pakistan). Keyless guided surgery drills (Smart Kit). Pakistan. (Figure 2A) Other

- Piezotome mectron Italy. (Figure 2B) using specialized Crest Splitting Tips.OT7. (Figure 2C)

-Ridge spreader kit (Dentium RS kit) will be used to perform the expansion. (Figure 2D)

\section{Methods}

Presurgical phase

\section{Clinical assessment}

First, bucco-lingual measurements were done using Cone Beam Computed Tomography (CBCT) (PaX-i3D Green, Vatech, USA) in order to check the eligibility of the patient to be enrolled in the study and fulfilling the inclusion criteria before further assessment. Scaling and oral hygiene measurements. Impressions will be taken. Fabrication of the interchangeable surgical guide stent.

An impression of the maxillary and mandibular arch were taken using alginate impression material (Hydrogum5, Zhermack SpA, Italy). Impressions were casted in dental stone (HTMDent dental stone type, Egypt) and were sent to the laboratory for preparation of the surgical stent. 
Optical scanning of the dental casts was done using Ceramill map 400 (Amman Girbach, Austria).

The treatment plan and the surgical stent were designed using Mimics Innovation Suite 19 тм software (Materialise Mimics software 3D Medical Imaging, Belgium). (Figure 3)

An interchangeable surgical guide was printed in resin using Dent1 dlp printer.

\section{Radiographic examination}

Cone beam Computed Tomography was used to define the alveolar ridge width, sites of implant placement, angulation, depth, and position of the ridge split.

\section{Surgical phase}

Scrubbing of the area of interest with Povidone-Iodine surgical scrub was done at the beginning of the procedure. All procedures were performed under local anesthesia (Mepivacaine hydrochloride 2 percent), augmented with infiltration anesthesia at implant site.

First, the surgical guide was placed and well adapted over the ridge after disinfection with suitable disinfectant (Figure 4A). No. 11 Bard Parker knife was then used to incise the mucosa at the slot area (of stent) midcrestally with the blade guide (Figure 4B). Care was paid to preserve the periosteum to avoid bone resorption and reduce possibility of free fracture of the split ridge. The initiating drill points were done guided by the drilling guide (Figure 4C). A midcrestal mesiodistal osteotomy was performed with the piezotome. assisted with the piezotome guide (Figure 4D). An unbeveled straight bone osteotome was inserted in the crestal osteotomy using a mallet to allow for a flapless split of the buccal plate of bone, using a split chisel guide (Figure 4E). Then, complete expansion with expanders (RS KIT) (Dentium RS KIT) (Figure 4F) was achieved successively according to the manufacturer's instructions. Following horizontal expansion, placement of the implant was done, with engagement of the basal bone for primary stability (Figure 4G, 4H). Then removal of the guide was performed prior to closure. Suturing by $3 / 0$ silk was done using a reverse cutting needle $26 \mathrm{~mm} 3 / 8$ c (Ghatwary medical supply GMS borg elarab, Alexandria, Egypt).

\section{Postsurgical phase}

\section{Postoperative instructions}

Cold foments over upper lip during the first 24 hours.

Warm antiseptic mouthwash 3 times daily for 1 week.

Strict oral hygiene measures.

Antibiotics: Augmentin (Augmentin: manufactured by GlaxosmithKline) (Amoxicillin 875 + Clavulanic acid 125) tablets: 1 tablet every 12 hours for 7 days postoperatively.

NSAID: Cataflam (Cataflam (50mg): manufactured by Novartis (Swiss multinational pharmaceutical company). www.Novartis.com) (diclofenac potassium $50 \mathrm{mg}$ ) tablets: 1 tablet every 12 hours for 5 days.

\section{Clinical evaluation}

Evaluation of the operative time was done. Clinical follow up was done immediately at 1 week after implant placement for any sign of swelling or infection and later at 6 months.
Pain was evaluated using visual analogue scale (VAS) from 0 to 10 ("0" is pain free and "10" is extremely painful).

\section{Radiographic evaluation}

Cone beam computed tomography (CBCT) was done at immediate and 6 months post-operatively to assess the actual implant position and measure bone width and density around implants.

Efficacy of the surgical guide was evaluated by a software with the aid of the pre and postoperative CBCT. The preoperative virtual plan was merged with the postoperative CBCT to define the deviations between the planned and placed crestal split and implants.

\section{Evaluation of accuracy}

Evaluation of accuracy of implant placement was done using Mimics Innovation Suite 19 тм software. The Preoperative virtual planning was superimposed to the postoperative CBCT imaging to measure the vertical (V), angular (A), and horizontal deviations at coronal (C) and apex (Ap) sides of the implant, between the virtually planned and actually inserted implants (Figure 5) (16).

Prosthetic Protocol

6 months post-operative CBCT was done. (Figure 6A)

Loading of the prosthesis was done 6 months postoperatively. (Figure 6B)

Statistical analysis

Data were analysed using IBM SPSS software package version 20.0. (Armonk, NY: IBM Corp). Qualitative data were described using number and percent. The KolmogorovSmirnov test was used to verify the normality of distribution of the data. Quantitative data were described using range (minimum and maximum), mean, standard deviation and median. The data compared were the position of the dental implant between the preoperatively virtually planned one and the actual implant placement position postoperatively with superimposition through comparing the angular and horizontal deviations. The used tests were ANOVA with repeated measures for normally distributed quantitative variables, to compare between more than two periods or stages, and Post Hoc test (LSD) for pairwise comparisons. Significance was set at a value of $\mathrm{p}<0.05$.

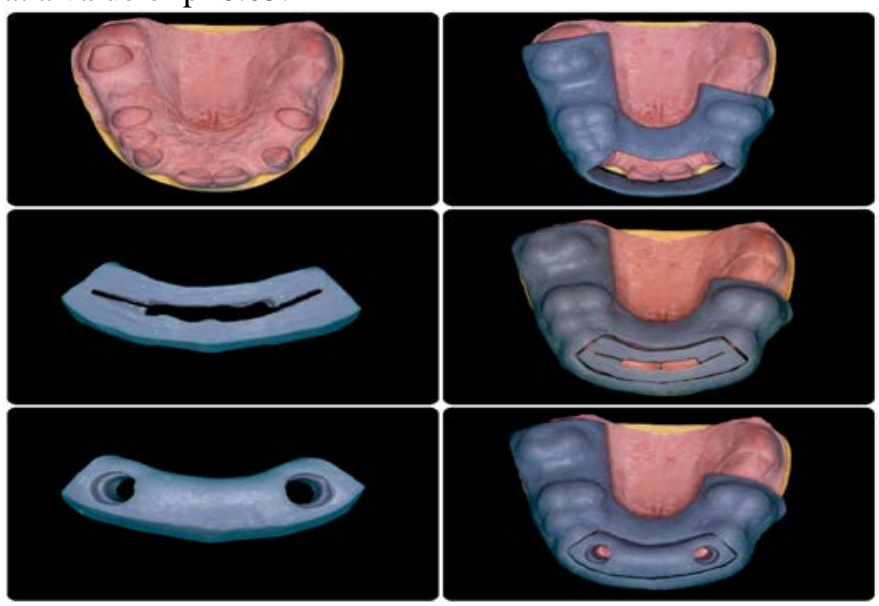

Figure (1): Interchangeable surgical guide. 
Elkholy et al.
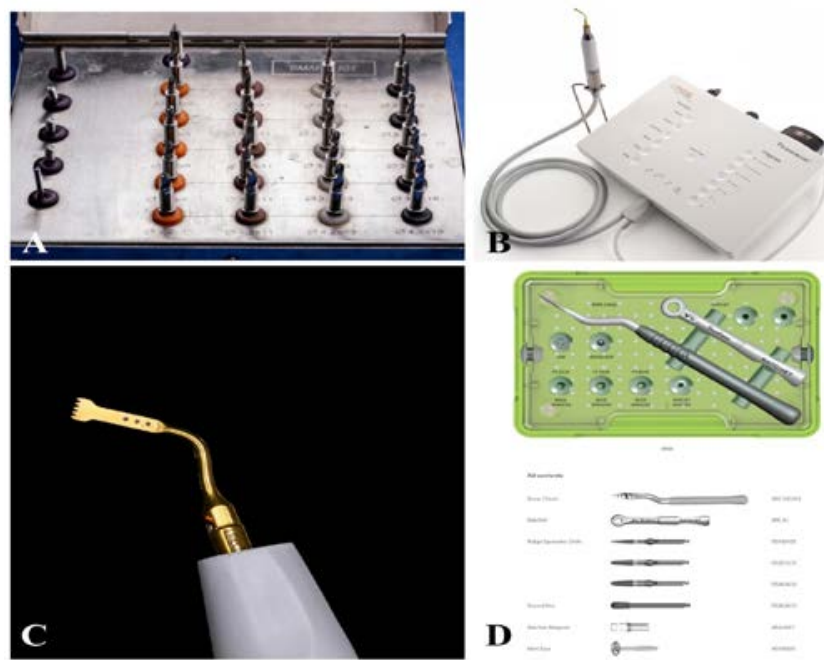

Figure (2): A) Universal Smart surgical kit. B) Piezotome mectron. C) Crest Splitting Tips.OT7. D) Ridge spreader kit

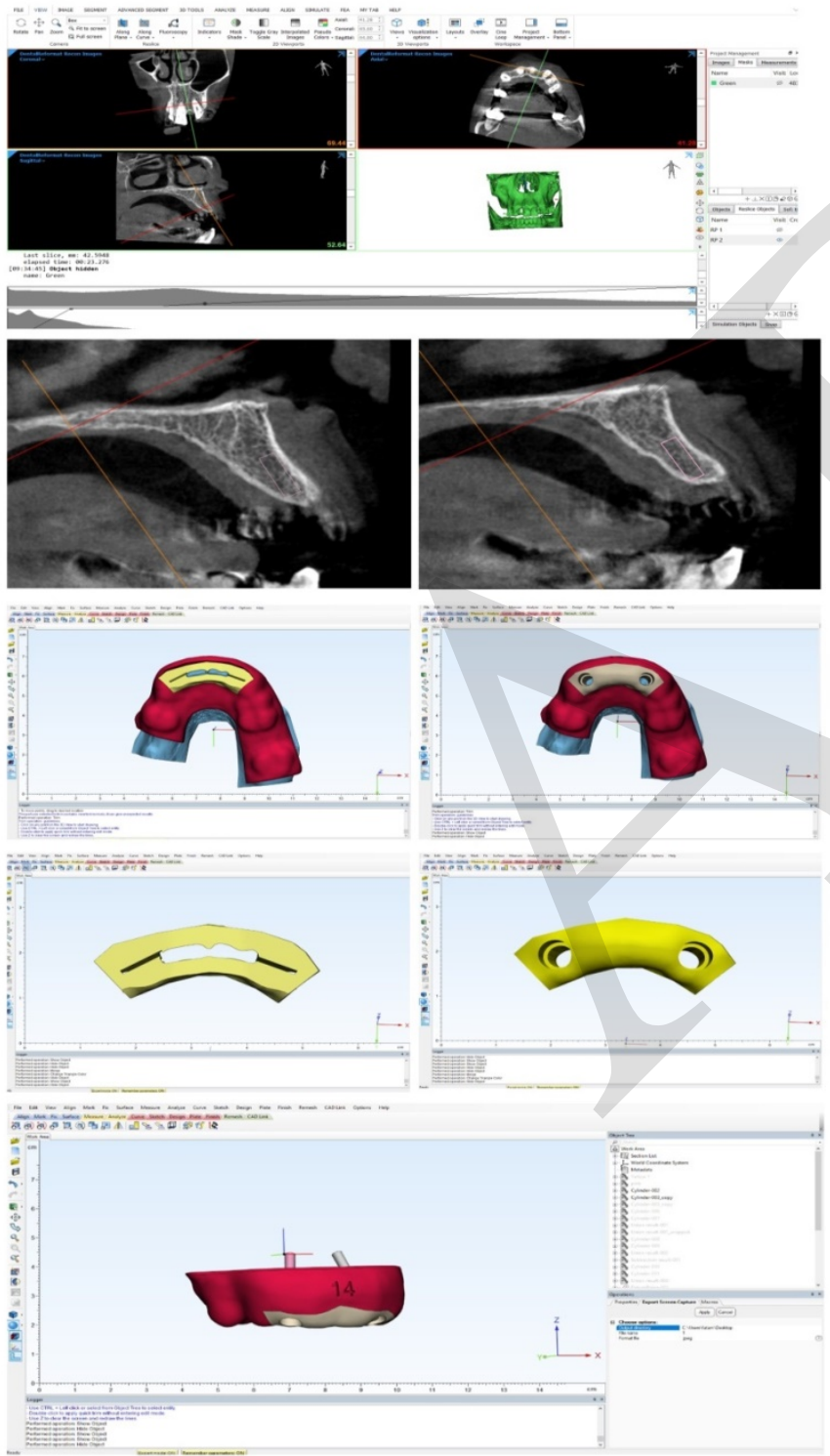

Figure (3): The treatment plan and the surgical stent were designed using Mimics Innovation Suite $19^{\mathrm{TM}}$ software.
Guided ridge splitting with simultaneous implant placement
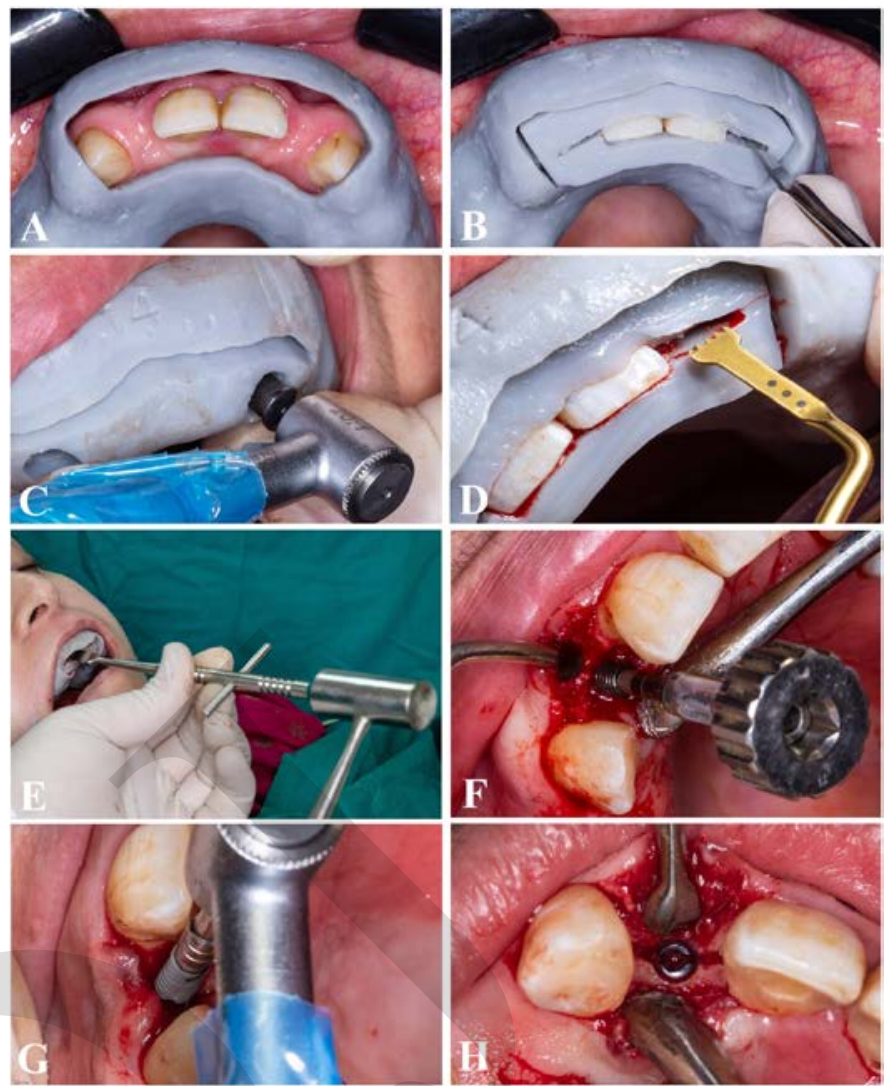

Figure (4): A) Stent on ridge. B) Blade guide. C) Drilling guide (initial drill). D) Piezotome osteotomy guide. E) Split chisel guide. F) Expansion with expanders (RS KIT). G,H) Implant-insertion.
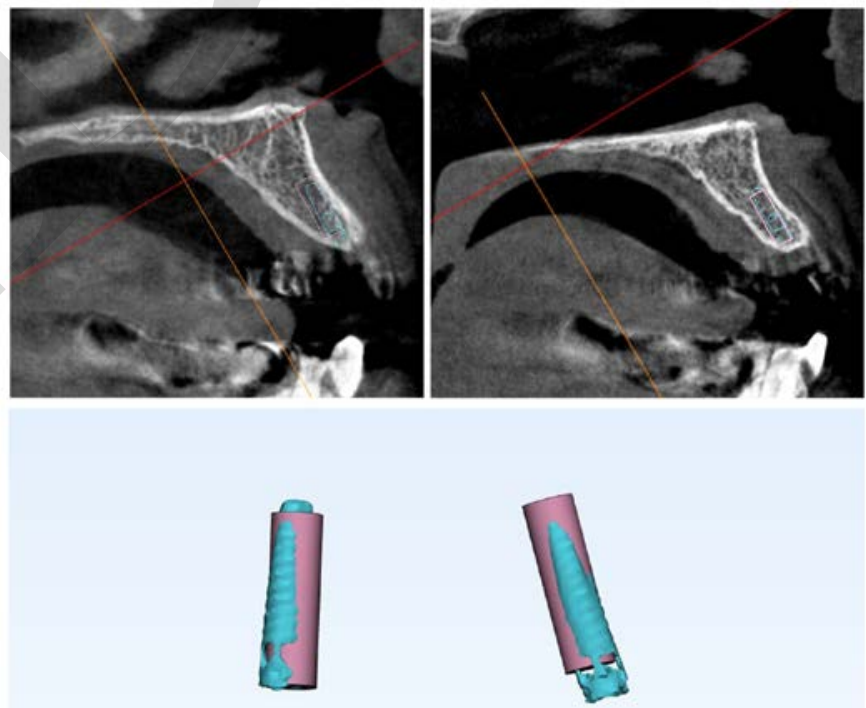

Figure (5): Sagittal and 3D views of a CBCT showing the actual implant in blue and the virtual one in red. 

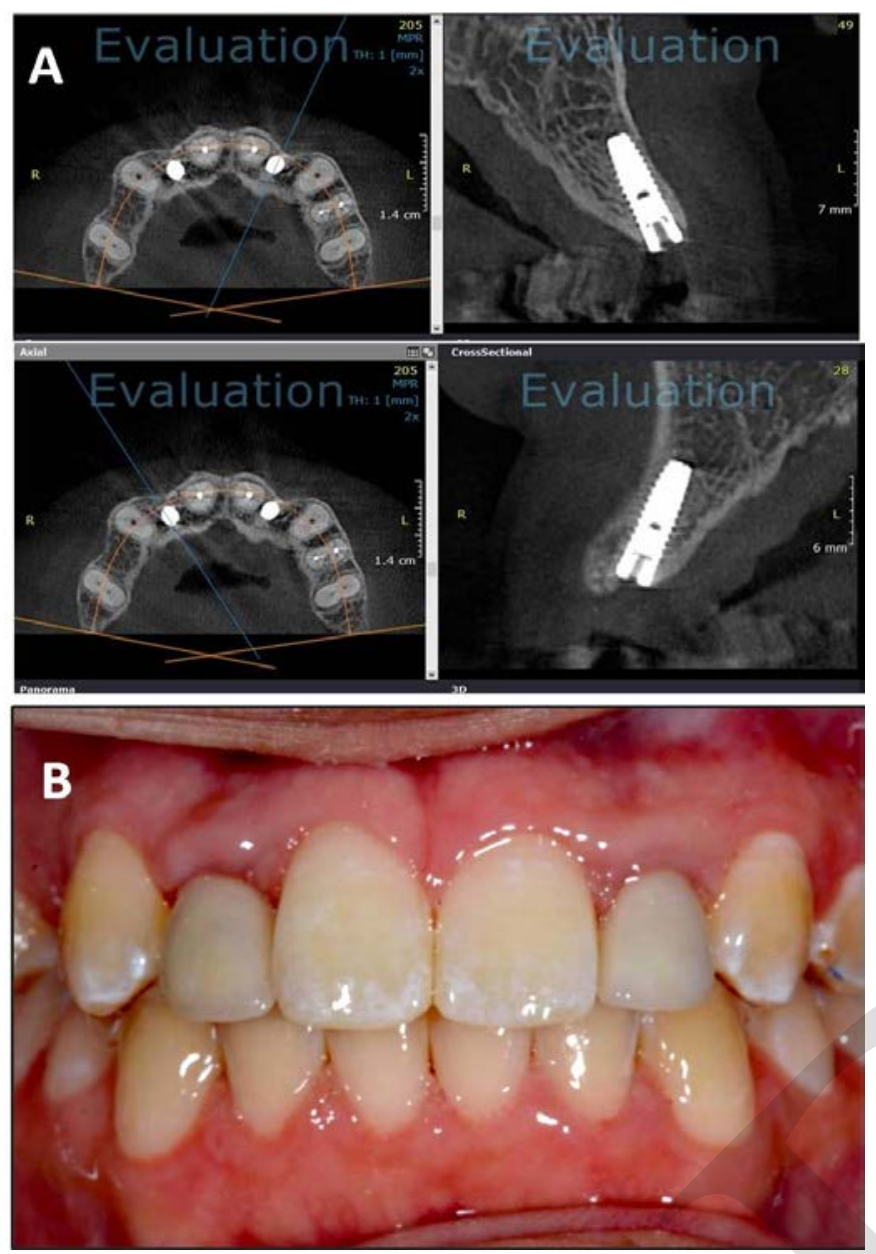

Figure (6): (A) Sagittal and axial views showing 6 months post-operative CBCT. (B) Final restoration.

\section{RESULTS}

A total five patients (3 females and 2 males) with 8 implants placed with minimally invasive technique assisted with an interchangeable surgical guide, were included. Their ages ranged from 20 and 40 years with an average of 31 years. The distribution of implant positions in the maxilla was 2 implants for maxillary central incisors and 6 implants for maxillary lateral incisor while no implants for maxillary canine.

Clinical evaluation

Regarding postoperative pain, two patients experienced mild pain (VAS $=4$ ) at the surgical site that subsided in two days, while the other three patients experienced no pain (VAS $=0$ ).

The operative time ranged from 15 to 45 minutes with an average of 25 minutes per implant. Other than mild hematoma in one patient that improved in two weeks, all subjects had a smooth postoperative course with no infection, gingivitis, or peri-implantitis.

Radiographic evaluation

Accuracy of implant placement

Angular, horizontal (coronal and apical) and vertical deviations, were measured for each of the 8 implants placed after superimposition of the postoperative CBCT to the virtual plan. The data for all measurements, averages, standard deviations were presented in table 1.

\section{Evaluation of angular deviation}

Results showed that Angular deviations between the long axis of the planned implants to the virtual implants (A) had a range of 0.51 - 4.52 degrees with an average of $2.61 \pm 1.46$ degrees.

Evaluation of the coronal deviation

The mean value of the horizontal deviation at the coronal side (C) of the implant was $0.70 \pm 0.46 \mathrm{~mm}$ with a range of 0.20 $1.35 \mathrm{~mm}$.

\section{Evaluation of apical deviation}

Horizontal deviations at the apex of the implants (Ap) had a range of $0.66-1.70 \mathrm{~mm}$ with an average of $0.98 \pm 0.35 \mathrm{~mm}$.

Evaluation of vertical deviation. Vertical deviations of the implants (V) had a range of $0.10-0.90 \mathrm{~mm}$ with an average of $0.39 \pm 0.29 \mathrm{~mm}$.

Evaluation of Bone

1-Bone width was assessed preoperatively, immediate postoperatively and at 6 months postoperatively as shown in Table 2. There were statistically significant differences between preoperative, immediate postoperative and 6 months postoperative values of bone width. Also, the immediate postoperative and 6 months postoperative values revealed a statistically significant difference.

The mean value of bone width measured preoperatively was $4.22 \pm 0.62 \mathrm{~mm}$ with a minimum value of $3.3 \mathrm{~mm}$ and a maximum value of $4.98 \mathrm{~mm}$. The immediate postoperative mean value was $6.18 \pm 1.15 \mathrm{~mm}$ with a minimum value of $4.32 \mathrm{~mm}$ and a maximum value of 7.59 $\mathrm{mm}$. Percentage of change is $45.71 \pm 10.74 \%$. At 6 months postoperatively, bone width was $6.58 \pm 1.16 \mathrm{~mm}$ with a minimum value of $5.10 \mathrm{~mm}$ and maximum value of $8.13 \mathrm{~mm}$. Percentage change from preoperative measurement is $55.54 \pm$ $9.75 \%$.

2-Bone density

All measurements of bone density; preoperative, immediate postoperative and 6 months postoperative are summarized in Table 3. There were statistically significant differences at preoperative, immediate postoperative and at 6 months postoperative follow up intervals.

Bone density measured preoperatively was $435.55 \pm$ $149.05 \mathrm{HU}$ with a minimum value of $236.26 \mathrm{HU}$ and a maximum value of $699.43 \mathrm{HU}$. Immediate postoperative bone density was $705.56 \pm 168.62 \mathrm{HU}$ with a minimum value of $527.88 \mathrm{HU}$ and a maximum value of $958.33 \mathrm{HU}$ and a percentage change of $73.37 \pm 47.17 \%$. 6 months postoperative bone width was $1170.82 \pm 153.12 \mathrm{HU}$ with a minimum value of $975.22 \mathrm{HU}$ and a maximum value of $1389.73 \mathrm{HU}$ and a percentage change of $193.6 \pm 87.91 \%$. 
Table (1): Descriptive analysis of the studied implants according to different parameters $(n=8)$

\begin{tabular}{|l|l|l|l|l|}
\hline \multirow{2}{*}{ No. } & Vertical & Angle & Apex & Coronal \\
\cline { 2 - 5 } & V (mm) & A $\left({ }^{\circ}\right)$ & Ap(mm) & C (mm) \\
\hline 1 & 0.60 & 0.51 & 0.70 & 1.20 \\
\hline 2 & 0.51 & 0.82 & 1.16 & 1.35 \\
\hline 3 & 0.10 & 3.77 & 0.97 & 0.45 \\
\hline 4 & 0.10 & 4.52 & 1.70 & 1.11 \\
\hline 5 & 0.30 & 3.77 & 0.70 & 0.20 \\
\hline 6 & 0.90 & 3.20 & 0.82 & 0.57 \\
\hline 7 & 0.48 & 2.52 & 1.15 & 0.50 \\
\hline 8 & 0.10 & 1.80 & 0.66 & 0.20 \\
\hline Mean & 0.39 & 2.61 & 0.98 & 0.70 \\
\hline SD. & 0.29 & 1.46 & 0.35 & 0.46 \\
\hline Median & 0.39 & 2.86 & 0.90 & 0.54 \\
\hline Min. & 0.10 & 0.51 & 0.66 & 0.20 \\
\hline Max. & 0.90 & 4.52 & 1.70 & 1.35 \\
\hline
\end{tabular}

Table (2): Comparison between the different studied periods according to bone width $(\mathrm{n}=8)$

\begin{tabular}{|c|c|c|c|c|c|}
\hline \multirow[b]{2}{*}{ Bone Width } & \multirow[b]{2}{*}{$\begin{array}{c}\text { Pre- } \\
\text { operative }\end{array}$} & \multicolumn{2}{|c|}{ Post-operative } & \multirow[b]{2}{*}{$\mathbf{F}$} & \multirow[b]{2}{*}{$\mathbf{p}$} \\
\hline & & Immediately & $\begin{array}{l}6 \\
\text { months }\end{array}$ & & \\
\hline $\begin{array}{l}\text { Min. - } \\
\text { Max. }\end{array}$ & $\begin{array}{c}3.33- \\
4.98\end{array}$ & $4.32-7.59$ & $\begin{array}{c}5.10- \\
8.13\end{array}$ & \multirow{3}{*}{$96.053^{*}$} & \multirow{3}{*}{$<0.001^{*}$} \\
\hline $\begin{array}{l}\text { Mean } \pm \\
\text { SD. }\end{array}$ & $\begin{array}{c}4.22 \pm \\
0.62\end{array}$ & $6.18 \pm 1.15$ & $\begin{array}{l}6.58 \pm \\
1.16\end{array}$ & & \\
\hline Median & 4.24 & 5.82 & 6.11 & & \\
\hline $\begin{array}{c}\% \text { of } \\
\text { change }\end{array}$ & & $\begin{array}{c}\uparrow 45.71 \pm \\
10.74\end{array}$ & $\begin{array}{c}\uparrow 55.54 \pm \\
9.75 \\
\end{array}$ & & \\
\hline $\begin{array}{l}\text { Sig. bet. } \\
\text { periods }\end{array}$ & \multicolumn{3}{|c|}{$\mathrm{p}_{1}<0.001^{*}, \mathrm{p}_{2}<0.001^{*}, \mathrm{p}_{3}=0.001^{*}$} & & \\
\hline
\end{tabular}

F: F test (ANOVA) with repeated measures, Sig. bet. periods was done using Post Hoc Test (LSD)

$\mathrm{p}_{1}$ : $\mathrm{p}$ value for comparing between pre-operative and immediately post-operative

$\mathrm{p}_{2}$ : $\mathrm{p}$ value for comparing between pre-operative and 6 months postoperative

$\mathrm{p}_{3}$ : $\mathrm{p}$ value for comparing between immediately post-operative and 6 months post-operative

*: Statistically significant at $\mathrm{p} \leq 0.05$

Table (3): Comparison between the different studied periods according to bone density in $\mathrm{HU}(\mathrm{n}=8)$

\begin{tabular}{|c|c|c|c|c|c|}
\hline \multirow{2}{*}{$\begin{array}{c}\text { Bone } \\
\text { density in } \\
\text { HU }\end{array}$} & \multirow[b]{2}{*}{$\begin{array}{c}\text { Pre- } \\
\text { operative }\end{array}$} & \multicolumn{2}{|c|}{ Post-operative } & \multirow[b]{2}{*}{$\mathbf{F}$} & \multirow[b]{2}{*}{$\mathbf{p}$} \\
\hline & & Immediately & $\begin{array}{l}6 \\
\text { months }\end{array}$ & & \\
\hline $\begin{array}{l}\text { Min. - } \\
\text { Max. }\end{array}$ & $\begin{array}{c}236.26- \\
699.43\end{array}$ & $\begin{array}{c}527.88- \\
958.33\end{array}$ & $\begin{array}{c}975.22 \\
- \\
-\end{array}$ & \multirow{3}{*}{$85.661^{*}$} & \multirow{3}{*}{$<0.001$} \\
\hline $\begin{array}{l}\text { Mean } \pm \\
\text { SD. }\end{array}$ & $\begin{array}{c}435.55 \pm \\
149.05\end{array}$ & $\begin{array}{c}705.56 \pm \\
168.62\end{array}$ & $\begin{array}{l}1170.82 \\
\pm \\
153.12\end{array}$ & & \\
\hline Median & 444.88 & 638.55 & 1141.11 & & \\
\hline $\begin{array}{c}\text { \% of } \\
\text { change }\end{array}$ & & $\begin{array}{c}\uparrow 73.37 \pm \\
47.17 \\
\end{array}$ & $\begin{array}{r}\uparrow 193.6 \\
\pm 87.91 \\
\end{array}$ & & \\
\hline $\begin{array}{l}\text { Sig. bet. } \\
\text { periods }\end{array}$ & \multicolumn{3}{|c|}{$\mathrm{p}_{1}=0.003^{*}, \mathrm{p}_{2}<0.001^{*}, \mathrm{p}_{3}<0.001^{*}$} & & \\
\hline
\end{tabular}

F: F test (ANOVA) with repeated measures, Sig. bet. periods was done using Post Hoc Test (LSD) $\mathrm{p}_{1}$ : $\mathrm{p}$ value for comparing between pre-operative and immediately post-operative

$\mathrm{p}_{2}$ : $\mathrm{p}$ value for comparing between pre-operative and 6 months post-operative

$\mathrm{p}_{3}$ : $\mathrm{p}$ value for comparing between immediately post-operative and 6 months post-operative

*: Statistically significant at $\mathrm{p} \leq 0.05$

\section{DISCUSSION}

Despite the great advancement and improvement in implant dentistry, still the narrow alveolar ridge constitutes a major obstacle and challenge for most clinicians. Various methods to augment the inadequate ridge have been advocated, of which, the ridge splitting technique gains popularity in such ridges with adequate height (4).

The current study presented a minimally invasive technique of ridge splitting guided with 3D designed surgical guide to augment the deficient alveolus in 5 patients with simultaneous 8 implant placements.

In our case series, the surgical guides were well placed over the reduced ridge therefore, obviating the use of anchor pins due to the presence of teeth, which prevented rotation and rocking of the guide during the drilling process.

In this case series, two patients underwent one implant inserted on each side, operated in 15 minutes. The other three patients underwent two implants, in a considerable time ranging from 15-45 minutes.

From the results of the current study, the mean value of deviations were better than those reported in previous reports, including the angular $(17,18)$, horizontal deviation at coronal $(17,19)$, and apex sides (17-21). Furthermore, the analysis of our results demonstrated that the horizontal deviations at the apical sides were higher compared to those at the coronal sides. This could be related to the greater control on the implant from the coronal part. Therefore, we assume the accuracy of the interchangeable guides presented in the current study was is accepted within the range of results of previous reports. Although, achieving better outcomes in the current study, still minor deviations were recorded that could be related to inaccurate planning, improper placement of the guide over the ridge, acquisition of tomographic image and improper guide fixation, in addition, minor mechanical errors due to use of bone expanders. Another critical factor sharing in the summation of errors is also encountered during different steps of manufacturing of the guide including, simulation, the accuracy of the stereolithography, physical properties of the material of the guide, and verification of the guide (22). Among all errors involved, the most critical is the inherent error arising from the mechanical component tolerance in the surgical guides (23).

Reviewing the literature, fewer reports have investigated the potential errors with inherent limitations of stereolithographic guides. However, it is still of great importance to investigate such errors and different mechanical contributing factors affecting the accuracy of positioning of the surgical guide in order to manufacture a guide with higher accuracy and stability and without displacement during the drilling (23).

It is well known in the field of virtual planning that errors add together in a cumulative way; so minor errors in 
different stages of planning augment till the final larger error is the scene. Accordingly, the most crucial point while planning a virtual design is the deviation value. As such, in order to increase the accuracy of virtual planning and reduce the errors reported, the surgeon should pay an attention to different types of errors, their timing and order in the procedure, and most importantly, the source of such errors, in order to avoid their occurrence. Various steps of the planning procedure have to be carefully considered to decrease such errors, including; patient movements while having CBCT scanning, and fitting during placement of the surgical guide (24).

The virtual planning technique is now gaining much popularity in the field of implantology, with a considerable reliability and success rate, although still some limitations are being encountered (25). The presented ridge splitting guided with 3D template achieves a significant increase in bone width and density at immediate and at 6 months postoperatively, such an important finding signifies the fact that this technique has a constant and reliable outcomes and avoids ongoing future bone resorption.

In the present study, the screw expanders were applied instead of the conventional osteotomes to expand the ridge and bone condensation preparing for implant placement. This alternative use of screw expanders allows for nontraumatic procedure that is reflected on minimizing the errors and enhancing the accuracy, through improving stability, maintaining density of bone and enhancing fixation. In addition, this leads to successful osseointegration owing to perfect bone condensation around the placed implant (26).

Manual screwing of the expanders is crucial in increasing the accuracy during the cortical approach. This method is not operator dependent and reduces the onset of adverse outcomes that result from hammering with traditional osteotomes (26). The screwing effect itself is responsible for the significant increase in bone width and density immediately after surgery.

The mean values of gained bone width were recorded immediately and 6 months postoperatively. The mean bone width value immediately postoperative was found to be $6.18 \pm$ $1.15 \mathrm{~mm}$ which was statistically significant). This shows that this technique shows noticeable and significant increase in bone width immediately postoperative. At 6 months postoperatively, the bone width value was $6.58 \pm 1.16$ which was statistically significant when compared to preoperative values but with no significance in comparison to immediately post-operative value. This clarifies that the present technique keeps the achievement gained immediately postoperative therefore avoiding further bone resorption.

The current study poses several advantages. First, the procedure saves a lot of time and avoids the use of larger flaps due to the minimally invasive nature of the technique. Second, minimal dissection preserves the periosteum, therefore, less bone resorption. Third, reduced bleeding results in minimal postoperative discomfort, and better satisfaction of the patient with the procedure (27). Forth, most importantly, is the use of the interchangeable surgical guide, which helps to guide the osteotomy precisely and meanwhile aids an accurate placement of dental implants. Therefore, the interchangeable surgical guide serves a dual function which saves time and increases the accuracy.

In addition, in computer-guided surgery, the accuracy of the procedure is less affected by the surgeon skills in comparison to the traditional technique (28). Moreover, the conventional technique shows various drawbacks as a result of over dissection of the tissues during flap raising including infections, dehiscence, and necrosis (29). Regarding bone resorption, the soft tissue flap is important for implant placement for sake of bone contact (30). Nevertheless, when bone quantity is adequate for implant placement, the flap is then unnecessary due to higher morbidity and patient's discomfort (30).

Although this method shows plenty of advantages, still this study has some limitations. First, the current study is based on a small sample size, hence the need for a further research with larger sample size to comprehensively advocate the outcomes with less bias. Second, the follow up period is relatively short. Third, the current report did not focused on evaluation of different implant stability and longevity parameters. Accordingly, we need to address a prospective clinical study including larger sample size with longer term follow up.

To summarize, this report introduces a ridge splitting technique assisted by an interchangeable guide which helped an accurate incision, osteotomy and drilling, guided by the slots in the surgical guide.

\section{CONCLUSIONS}

From the outcomes of the current case series, the 3D guided ridge splitting procedure is a reliable method that helps to augment the inadequate ridge with an enhanced accuracy. Being minimally invasive, this technique aids to preserve the periosteum therefore reducing postoperative complications. Moreover, the guided ridge splitting achieves better outcomes regarding bone width and density.

\section{CONFLICT OF INTEREST}

The authors sharing in this work declare no conflicts of interest.

\section{REFERENCES}

1. Takeshita F, Suetsugu T. Accurate presurgical determination for implant placement by using computerized tomography scan. J Prosthet Dent. 1996;76:590-1.

2. Scipioni A, Bruschi GB, Calesini G. The edentulous ridge expansion technique: a five-year study. Int $\mathrm{J}$ Periodontics Restorative Dent. 1994;14:451-9.

3. Von Arx T, Kurt B. Implant placement and simultaneous ridge augmentation using autogenous bone and a micro titanium mesh: A prospective clinical study with 20 implants. Clin Oral Implants Res.1999;10:24-33.

4. Chiapasco M, Zaniboni M, Boisco M. Augmentation procedures for the rehabilitation of deficient edentulous ridges with oral implants. Clin Oral Implants Res. 2006;17:136-59. 
5. Castillo R. Horizontal ridge augmentation before placing implants using a double-bone, double resorbable membrane technique: Two clinical cases. Eur J Esthet Dent. 2010;5:340-56.

6. Mechery R, Thiruvalluvan N, Sreehari AK. Ridge split and implant placement in deficient alveolar ridge: Case report and an update. Contemp Clin Dent. 2015;6:94-7.

7. Israelson H, Plemons JM, Watkins P, Sory C. Bariumcoated surgical stents and computer-assisted tomography in the preoperative assessment of dental implant patients. Int J Periodontics Restorative Dent. 1992;12:52-61.

8. Greenstein G, Cavallaro J. The relationship between biological concepts and fabrication of surgical guides for dental implant placement. Compend Contin Edu Dent. 2007;28:196-204.

9. Malo P, de Araujo Nobre M, Lopes A. The use of computer guided flapless implant surgery and four implants placed in immediate function to support a fixed denture: preliminary results after a mean follow-up period of thirteen months. J Prosth Dent. 2007;97:S2634.

10. Richardson D, Cawood JI. Anterior maxillary osteoplasty to broaden the narrow maxillary ridge. Int $\mathrm{J}$ Oral Maxillofac Surg. 1991;20:342-8.

11. Zhang W, Skrypczak A, Weltman R. Anterior maxilla alveolar ridge dimension and morphology measurement by cone beam computerized tomography (CBCT) for immediate implant treatment planning. BMC Oral Health. 2015;15:65.

12. Forsell M, Sjögren P, Johansson O. Need of assistance with daily oral hygiene measures among nursing home resident elderly versus the actual assistance received from the staff. Open Dent J. 2009;3:241-4.

13. Sivapathasundharam B. Shafer's Text Book of Oral Pathology. $8^{\text {th }}$ ed. India: Elsevier; 2016.

14. Abramson JH. Cornell medical index as an epidemiologic tool. Am J Public Health Nations Health. 1966;56:287-98.

15. Wilson D, Wakefield M, Owen N, Roberts L. Characteristics of heavy smokers. Prev Med. 1992;21:311-9.

16. Chasioti E, Sayed M, Drew H. Novel Techniques with the Aid of a Staged CBCT Guided Surgical Protocol. Case Rep Dent. 2015;2015:439706.

17. Di Giacomo GA, Cury PR, de Araujo NS, Sendyk WR, Sendyk CL. Clinical application of stereolithographic surgical guides for implant placement: preliminary results. J Periodontol. 2005;76:503-7.

18. Cunha RM, Souza FA, Hadad H, Poli PP, Maiorana C, Carvalho PSP. Accuracy evaluation of computer-guided implant surgery associated with prototyped surgical guides. J Prosthet Dent. 2020; S0022-3913(19)30486-X.

19. Farley NE, Kennedy K, McGlumphy EA, Clelland NL. Split-mouth comparison of the accuracy of computergenerated and conventional surgical guides. Int $\mathrm{J}$ Oral Maxillofac Implants. 2013;28:563-72.

20. Schneider D, Marquardt P, Zwahlen M, Jung RE. A systematic review on the accuracy and the clinical outcome of computer-guided template-based implant dentistry. Clin Oral Implants Res. 2009;20:73-86.

21. D'haese J, Van De Velde T, Komiyama A, Hultin M, De Bruyn H. Accuracy and complications using computerdesigned stereolithographic surgical guides for oral rehabilitation by means of dental implants: a review of the literature. Clin Implant Dent Relat Res. 2012;14:32135.

22. Mustafa MN, Khalil AF, Melek LN. Evaluation of piezotomed alveolar ridge splitting with stereolithographic surgical guide for implant placement (clinical study). FDJ. 2017;3:47-54.

23. Cassetta M, Di Mambro A, Di Giorgio G, Stefanelli LV, Barbato E. The Influence of the Tolerance between Mechanical Components on the Accuracy of Implants Inserted with a Stereolithographic Surgical Guide: A Retrospective Clinical Study. Clin Implant Dent Relat Res. 2015;17:580-8.

24. Neugebauer J, Traini T, Thams U, Piattelli A, Zöller JE. Peri-implant bone organization under immediate loading state. Circularly polarized light analyses: aminipig study. J Periodontol. 2006;77:152-60.

25. Ewers R, Schicho K, Undt G, Wanschitz F, Truppe M, Seemann R, et al. Basic research and 12 years of clinical experience in computer-assisted navigation technology: a review. Int J Oral Maxillofac Surg. 2005;34:1-8

26. Guillemant H, Mouigha A, Vienne A, Libersa JC, Ferri J. Contribution and limitations of MIS(R) screwed expanders in the jaws: illustration from clinical cases and comparison of the osseous volume from threedimensional radiographic pictures. Rev Stomatol Chir Maxillofac. 2012;113:448-54.

27. Kumar D, Sivaram G, Shivakumar B, Kumar T. Comparative evaluation of soft and hard tissue changes following endosseous implant placement using flap and flapless techniques in the posterior edentulous areas of the mandible-a randomized controlled trial. Oral Maxillofac Surg. 2018;22:215-23.

28. Widmann G, Bale JR. Accuracy in computer-aided implant surgery --a review. Int J Oral Maxillofac Implants. 2006;21:305-13.

29. Becker W, Goldstein M, Becker BE, Sennerby L. Minimally invasive flapless surgery: a prospective multicenter study. Clin Implant Dent Relat Res. 2005;7:S21-7.

30. Lemos CAA, Verri FR, Cruz RS, Gomes JML, Dos Santos DM, Goiato MC, Pellizzer EP. Comparison between flapless and open-flap implant placement: a systematic review and meta-analysis. Int $\mathrm{J}$ Oral Maxillofac Surg. 2020;49:1220-31. 